\title{
Combinatorial Optimization in Condition Based Maintenance System
}

\author{
Akpan W. $\mathrm{A}^{1^{*}}$, Odukwe A. $\mathrm{O}^{2}$, Anl. O. $\mathrm{I}^{3}$ \\ ${ }^{1}$ Mechanical and Aerospace Engineering Department, University of Uyo, Nigeria. \\ ${ }^{2}$ Mechanical Engineering Department University of Nigeria Nsukka, Nigeria. \\ ${ }^{3}$ Mechanical / Production Engineering Department, Enugu State University of Science and \\ Technology, Esut, Nigeria.
}

*Corresponding Author: Akpan W. A, Mechanical and Aerospace Engineering Department, University of Uyo, Nigeria.

\begin{abstract}
This study investigates a problem of machine inspection and condition monitoring (CM) for condition based maintenance (CBM) management in an oil flow station. A proposed combinatorial optimization cost model is presented. The total expected condition based maintenance cost model for the system include the condition monitoring instrument cost, inspection cost and the failure cost. The optimum inspection interval that minimizes the total expected CBM cost (TEC) for the system is three months for the three machines. The results show the efficacy of combinatorial optimization in CBM management system. This approach is highly recommended for CBM management of this flow station and similar systems.
\end{abstract}

Keywords: Combinatorial Optimization, Inspection, CM, CBM, maintenance scheduling.

\section{INTRODUCTION}

The maintenance approach best suited to an item can be determined using the reliability centered maintenance (RCM) methodology. It provides a structure for determining the maintenance requirement of any physical asset in its operating contest, with the primary objective of preserving system function cost effectively (Moubrary, 2002). Identification of system functions and functional failures, as well as failure mode and effects analysis are important elements in RCM.

Hazard identification can be performed by means of checklist: Failure Mode Effect Analysis (FMEA), Failure Mode Effect and Criticality Analysis (FMECA) and also Fault Tree Analysis (FTA). It is useful to identify individual and asset risk and when the most serious risk sources are of interest. AlNajjair (1991) suggested that in order to identify the maintenance significant factor (MSIs) of a system, a comprehensive survey of all consisting items of the system should be carried out, which is often done by FMECA. For example, one way of selecting a significant item is dependent on the value of the Risk Priority Number (RPN).

F1 - is the failure intensity, FC- is the failure criticality and FDF is the probability that a failure is not detected. If the RPN of an item exceeds a certain predetermined value, then such an item is considered to be a maintenance significant item and if not a non-significant item. The most appropriate maintenance strategy for a non-significant item is failure-based maintenance.

Once the maintenance significant items are identified, all condition parameters which describe the condition or performance of each MSI, are determined. A condition parameter is defined as a measurable variable to display directly or reflect indirectly information about the condition of an item or system at any instant of operating time (Haritha, 2002). It is always advantageous to find as many condition parameters as possible, which can accurately reflect the condition of the item. But if it is not possible to monitor the condition of the item, due to practical or economic reasons, then the optimum maintenance strategy is time-based maintenance.

Haritha (2002) showed how relevant condition predictor can be determined. If the condition parameter of the item is available, then we can determine it to know if it is relevant condition indicator or a 
relevant condition predictor. A condition parameter, which describes the condition of an item during operating time and indicates the condition of the item at the instant of checking, is called a Relevant Condition Indicator (RCI). The CI is usually related to the performance of the item as it indicates the state of the item at the time of inspection of the item. A condition parameter that describes the condition of the item at every instant of operating time is called a Relevant Condition Predictor- RCP (Haritha, 2002).

In general, RCP is directly related to shape, geometry, weight and other characteristics of the item under consideration. Examples of RCP are crack length, wall thickness of pipe etc.

Haritha (2002) maintained that if the condition parameter on the item is a RCI, then the optimum maintenance strategy for the item is condition based maintenance (inspection task). In such a case, the most suitable frequency of inspection, $T_{i}$ to examine the RCI and critical level of the relevant condition indicator $R C I^{C T}$ are determined even before the item is introduced into service. Thus, while the MSI is under operation, inspections are performed at the specified interval $T_{i}$, until the criticality level of the relevant condition indicator $R C I^{C T}$ is reached. Once $\operatorname{RCI}\left(T_{i}\right)>R C I^{C T}$, the preventive maintenance is performed - the condition based maintenance task is performed and then the item is restored to its original condition (Haritha, 2002).

Condition based maintenance (CBM) is an equipment maintenance procedure based on detecting the condition of the equipment in order to evaluate whether it will fail during some future period and then acting appropriately to avoid the consequence of that failure (Bengston, 2004). It is maintenance action furthered on actual condition derived from tests. Maintenance is not carried out until there is an obvious need which will increase the availability of the equipment, as well as lower the maintenance cost. The acquired data could be used to determine whether the system is running at a normal operating condition. If the limits of the preset values are exceeded, the reason behind it can be adduced and prediction made for future equipment breakdown and failure. The available information is used to plan maintenance actions (Bengston, 2004). The system/component could be monitored continuously, in which case, the monitoring equipment is fixed on the system and connected to the computer for real time monitoring. On the other hand, the monitoring equipment can be a hand held device out in the field or manufacturing system and the data taken at intervals and analysed afterwards. It is how the information is used that determines if condition based maintenance is in place. Conditioned based maintenance requires taking the result of the analysis and planning the maintenance afterwards. Utilization and communication of condition monitoring data within the establishment requires a structure (Evans, 2003).

Condition monitoring is important to the maintenance manager as it allows it plan preventive work ad possible serious consequences of breakdown (Koboa-Aduma 1991).Condition monitoring otherwise known as predictive maintenance has planned maintenance strategy a step further to rationality and has been found to reduce maintenance cost by $45 \%$ (Guerin,1977). The typical purpose of condition monitoring is to identify potential catastrophic failure with the intension to accurately schedule urgent maintenance activity so as to prevent operational interruption.(Laakso, et al; 2002). The sophistication of most of the techniques and the problems associated with their use reduces the advantages of predictive maintenance. Failures in the industry can be classified as mechanical, thermal or chemical (Banga et al;1992). Mechanical failure may be due to bad or worn out bearing, creep of materials at high temperatures subjected to stresses, fatique of machines members, excessive force due to misalignment and unbalance rotors, excessive induced vibrations caused by eddies and turbulence while fluid is flowing. In order to anticipate mechanical failures, the maintenance term must be equipped with instruments such as meter, shockpules meter, vibration analyzer, mechanical or electrical strain guage, and ultrasonic flow detector .A vibration analyst measures the amplitude of vibration at different frequencies so as to know the reason for undue high vibrations. A mechanical or electrical strain guage measures deflection of critical structural parts like foundations. Columns, etc. An ultrasonic flow detector $t$ detects minute cracks. Thermal failures are due to overheating because of the following reasons: electrical insulation failures, lack of lubrication, inadequate cooling. In order to anticipate thermal failures maintenance team must be equipped with instruments such as infrared thermometer and thermovision. An infrared thermometer detects hot spots in bearings and other parts of the machinery by remote sensing. A thermovision is an instrument, which scans the surface of a 
particular piece of equipment with infrared thermometer and displays o the video screen. Chemical failures may be due to corrosion or erosion as a result of failure of protective linings like glass, rubber etc. These may also be due highly corrosive or corrosive fluids containing abrasive particles. In order to anticipate chemical failures, the maintenance team must be equipped with instrument such as ultrasonic flow meter, ultrasonic leak detectors, ultrasonic or eddy current meter, An ultrasonic flow meter measures flow of liquids in pipes, heat exchangers etc. to know the extent of shocking etc. An instrument leak detector helps to detect of gases at high pressure, which cannot be otherwise seen or heard. An ultrasonic or eddy current thickness meter measures the thickness of paints, coatings etc, It can be used also to measure the thickness of pipes and tubes for finding out wear rates.

A good record keeping is essential for a condition monitoring system to be successful. For this purpose the following records are generally maintained namely-times of monitoring, raw data from such monitoring, results of analysis, frequency of breakdowns and maintenance work carried out. With the help of these records possible cause for major repetitive failures can be examined and rectified before they re-occur. According to Banga et al; (1992) analysis made on the basis of these records help in preventing defects rather than rectifying after breakdowns, knowing the machines reliability and thus helping in production planning, deciding life of the machine, forecasting defects and planning to rectify them before the failure occurs, deciding frequency of inspection and check ups, and finally in deciding the purchase time of a machine. Note that in spite of best planned and condition monitoring measures failures are bound to occur but they can be reduced to a large extent. The essential of asset monitoring and condition based maintenance are to increase the reliability and availability of the component/system. Maintainability is improved as more timely information on the condition of the assets are gotten thus enabling maintenance personnel, spares and other resources to be made available ahead of time before degradation reaches its specified limit. The majority of these techniques rely on the fact that most failures give some warning that they are about to occur. These warnings are known as potential failures (Moubray, 2002). It is identifiable physical conditions which indicate that a functional failure is about to occur or is in the process of occurring.

Akpan, et al; 2017 presented and solved a CBM problem for a system subject to inspection.

The objective of this work is to propose a model for an inspection based condition monitoring using combinatorial optimization for a three machine system. Combinatorial optimization is the process of searching for maxima or minima of an objective function whose domain is a discrete but large configuration space.

\section{Methodology}

Three machines in a flow station of a major oil company in Nigeria were used in the case study. It is kept anonymous for privacy policy. Data were obtained from this source. Elaborate discussions were made with managers, supervisors, engineers and maintainers on CBM implementation in the organization. Combinatorial optimization was used as a method of solution.

\section{Risk MODElS AND COMBINATORIAL OPTIMIZATION}

In this study an exponential distribution is assumed.

$$
f_{i}(t)=\lambda_{i} e^{-\lambda_{i i} t}
$$

Where $\lambda_{i}$ is the failure rate of the CM component in machine $i$.

Where $n_{f i}$ the actual is number of failure of machine $\mathrm{i}$ in a planning horizon.

$\mathrm{T}$ is the time unit (in this case one year)

$$
\lambda_{i}=\frac{1}{M T B F_{n i}}
$$

Where the mean time to failure is given as

$$
\operatorname{MBTF}_{n i}=\frac{U_{T}}{n_{f i}}
$$


$U_{T}$ is the uptime of machine $\mathrm{i}$

The cumulative distribution function (CDF) of the failure distribution represents the probability that a system fails before a given or expected period of time $t$, that is

$\bar{F}\left(t_{i j}\right)=1-F_{i, j}(t)$

For an exponential distribution,

$F_{i, j}(t)=\int f_{i}(t) d t$

The CBM model had been presented and solved by Akpan, et al; (2017).

$T E C=A_{v}+\sum_{i=1}^{N} \frac{T}{T_{i}} a_{i}+\sum_{i=1}^{N} \sum_{j=o}^{n-1_{i}} C_{i d i, j+1}+\sum_{i=1}^{N} \sum_{j=0}^{n-1_{i}} C_{i, j+1}$

where TEC is the total expected cost of the system

And,

$C P T=\frac{A_{v}}{T}+\sum_{i=1}^{N} \frac{a_{i}}{T_{i}}+\sum_{i=1}^{N} \sum_{j=0}^{n_{i}-1} \frac{C_{i d i, j+1}}{T}+\sum_{i=1}^{N} \sum_{j=0}^{n-1_{i}} \frac{C_{i, j+1}}{T}$

CPT is the average cost per month

$A_{v}, a_{i}, C_{i d i, j+1}$ and $C_{i, j+1}$ are given below:

$A_{v}=P / n_{m}$

$A_{v}$ is the depreciation cost, $\mathrm{P}$ is the acquisition cost, $n_{m}$ the planned years of replacement

$a_{i}=C_{L} t_{\text {inspect }_{\mathrm{i}, \mathrm{j}}}$

$a_{i}$ is the inspection cost of machine $\mathrm{i}, C_{L}$ labour cost and $t_{\text {inspect }}$, time to inspect machine $\mathrm{i}$

$C_{i d i, j+1}=P_{L} t_{d m i}$

$C_{i d i, j+1}$ is the down time cost of machine $\mathrm{i}$ in interval $\mathrm{j}, P_{L}$ is the production loss and $t_{d m i}$, the down time for production loss.

The failure cost $C_{i, j+1}$ is expressed as:

$C_{i, j+!}=\frac{r_{i}\left(1-e^{-\lambda_{i} t_{i, j+!}}\right)+s_{i}\left(t_{i, j+!}\right)+s_{i} t_{i, j+1} e^{-\lambda_{i} t_{i, j+1}}-\frac{s_{i}}{\lambda_{i}}\left(1-e^{-\lambda_{i} t_{i, j+1}}\right)}{e^{-\lambda_{i} t_{i, j+1}}}$

where:

$r_{i}$ is the repair cost, $s_{i}$ the increased cost of running the machine above alarm limit , $t_{i, j+1}$ the time interval

A combinatorial optimization technique is used as a method of solution in this study.

The formulation is:

Minimize the CBM cost (TEC)

$T E C=A_{v}+\sum_{i=1}^{N} \frac{T}{T_{i}} a_{i}+\sum_{i=1}^{N} \sum_{j=o}^{n-1_{i}} C_{i d i, j+1}+\sum_{i=1}^{N} \sum_{j=0}^{n-1_{i}} C_{i, j+1}$

Subject to

$T_{i}=K_{i} T_{o}$

$A_{v}, a_{i}, C_{i d i, j+1}$ and $C_{i, j+1}$ are given as in equations 8 to 11. 
$K_{i}$ is an integer, $T_{o}$ is the basic cycle, $T_{i}$ is the inspection interval of machine i. Further possible combinations of $T_{i}$ are generated with multiple of $T_{o}$, e.g. $2 T_{0}$ and $3 T_{0}$.

\section{RESUltS AND DiSCUSSION}

The system has two pumps (M/C1, M/C2) and one generator (M/C3). The system's characteristics are presented below:

$\mathrm{T}=1$ year

$T_{0}=1$ month basic cycle

$T_{1}=1$ month- inspection interval for all the machines

$\mathrm{N}=3$

$r_{1}=\mathrm{N} 2,733,333, r_{2}=\mathrm{N} 2,573,333, r_{3}=\mathrm{N} 1,240,000$

$s_{1}=\quad N 683,333\left(25 \% r_{1}\right), s_{2}=N 643,333\left(25 \% r_{2}\right), s_{3}=\mathrm{N} 310,000\left(25 \% r_{3}\right)$

$\lambda_{1}=0.00011 / \mathrm{hr}(1 / \mathrm{yr}),. \lambda_{2}=0.00023 / \mathrm{hr}(2 / \mathrm{yr}),. \lambda_{3}=0.00023 / \mathrm{hr}(2 / \mathrm{y})$

$n_{i}=12$, one month inspection interval, $n_{i}=6$, for two months inspection interval, $n_{i}=4$,

for three months inspection interval.

$P=\mathrm{N} 33,277,200, A_{v}=\mathrm{N} 6,655,440, n_{m}=5$ years

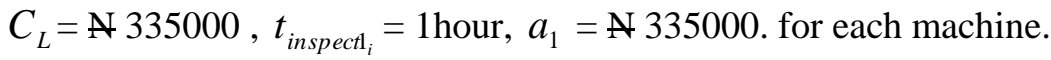

The one month, two months and three months for the system are presented in tables 1,2 and 3 respectively.

Table1. Expected Failure Cost for 1 Month Inspection Interval.

\begin{tabular}{|lcccc|}
\hline & & \multicolumn{4}{c|}{ Months/ Failure Cost (N) } \\
Month(s) & Machine 1 & Machine 2 & Machine 3 & $\sum_{1}^{4} C_{i, j}$ \\
\hline 1 & & & & \\
2 & $240,045.41$ & $471,695.11$ & $227,293.53$ & $939,034.05$ \\
3 & $506,330.36$ & $1,040,422.84$ & $501,343.72$ & $2,048,096.02$ \\
4 & $801,602.61$ & $1,725,864.14$ & $831,634.13$ & $3,359,100.88$ \\
5 & $1,128,889.30$ & $2,551,647.04$ & $1,229,550.31$ & $4,910,086.65$ \\
6 & $1,491,524.82$ & $3,546,131.09$ & $1,708,757.73$ & $6,746,413.64$ \\
7 & $1,893,181.29$ & $4,743,346.35$ & $2,285654.30$ & $8,345,284.97$ \\
8 & $2,337,902.14$ & $6,184,117.47$ & $2,979,912.00$ & $11,501,193.61$ \\
9 & $2,830,138.85$ & $7,917,408.83$ & $3,815,125.09$ & $14,562,672.77$ \\
10 & $3,374,791.40$ & $10,001,934.33$ & $4,819,585.75$ & $18,196,311.48$ \\
11 & $3,977,252.54$ & $12,508,083.10$ & $6,027,212.08$ & $22,512,547.72$ \\
12 & $4,643,456.49$ & $15,520,223.25$ & $7,478,658.14$ & $27,642,337.88$ \\
$\sum_{1}^{12} C_{i, j}$ & $5,379,969.43$ & $19,139,647.21$ & $9,222,733.26$ & $33,742,349.9$ \\
\hline
\end{tabular}


The total failure cost is $155,083,065.457$

Table 2 shows the failure cost for two months inspection interval for this system.

Table2. Expected Failure Cost for 2 Months Inspection Interval.

\begin{tabular}{|lllll|}
\hline \multicolumn{5}{c}{ Months/Failure Cost (N) } \\
Months & Machine 1 & Machine 2 & Machine 3 & $\sum_{1}^{3} C_{i, j}$ \\
\hline 2 & $506,333.73$ & $1,040,430.33$ & $501,347.32$ & $2,048,111.38$ \\
4 & $1,128,897.57$ & $2,551,668.76$ & $1,229,560.77$ & $4,910,127.1$ \\
6 & $1,893,196.50$ & $4,743,393.57$ & $2,285,677.05$ & $8,922,267.12$ \\
8 & $2,830.163 .70$ & $7,917,499.95$ & $3,815,169.00$ & $14,562,832.65$ \\
10 & $3,977,290.54$ & $12,508,247.73$ & $6,027,291.41$ & $22,512,829.68$ \\
12 & $3,977,290.54$ & $19,139,647.21$ & $9,222,733.26$ & $32,339,671.01$ \\
$\sum_{1}^{6} C_{i, j}$ & $15,715,851.458$ & $47,900,887.547$ & $23,081,778.818$ & \\
\hline
\end{tabular}

The total failure cost is $\mathrm{N} 86,698,517.823$.

Table 3 shows the failure cost for three months inspection interval for the system.

Table3. Expected Failure Cost for 3 Months inspection Interval for.

\begin{tabular}{|c|c|c|c|c|c|}
\hline \multirow{2}{*}{\multicolumn{2}{|c|}{$\begin{array}{l}\text { Machine } \\
\text { Months }\end{array}$}} & \multicolumn{4}{|c|}{ Months/Failure Cost (N) } \\
\hline & & Machine 1 & Machine 2 & Machine 3 & $\sum_{1}^{3} C_{i, j}$ \\
\hline 3 & 801,6 & 606.34 & $1,725,873.15$ & $831,638.48$ & $3,359,117.97$ \\
\hline 6 & 1,89 & $93,191.43$ & $4,743,377.83$ & $2,285,669.47$ & $8,922,238.73$ \\
\hline 9 & 3,37 & $74,812.01$ & $10,002,016.50$ & $4,819,625.35$ & $18,196,453.86$ \\
\hline 12 & & $379,969.43$ & $19,139,647.21$ & $9,222,733.26$ & $33,742,349.9$ \\
\hline \multicolumn{6}{|c|}{$\sum_{1}^{4} C_{i, j} \quad 11,449,579.209 \quad 35,610,914.697 \quad 17,159,666.553$} \\
\hline
\end{tabular}

The total failure cost is: N64, 220,160.458

The total expected cost and various combinations for the system are presented in table 4 .

Table4. TEC Cost and Various Combinations.

\begin{tabular}{|l|l|l|l|}
\hline S/N & Combinations & Total Expected Cost $(\mathbf{N})$ & $\begin{array}{l}\text { Average Cost per } \\
\text { Month(N) }\end{array}$ \\
\hline 1 & $T_{1}=T_{2}=T_{3}=T_{0}$ & $173,798,554.00$ & $14,483,212.83$ \\
\hline 2 & $T_{1}=T_{2}=T_{3}=2 T_{0}$ & $99,383,946.06$ & $8,281,995.51$ \\
\hline 3 & $T_{1}=T_{2}=T_{3}=3 T_{0}$ & $74,895,600.76$ & $6,241,300.06$ \\
\hline 4 & $T_{1}=2 T_{0}, T_{2}=T_{3}=T_{0}$ & $158,899,300.714$ & $13,241,608.40$ \\
\hline 5 & $T_{2}=2 T_{0}, T_{1}=T_{3}=T_{0}$ & $134,338,900.678$ & $11,194,908.39$ \\
\hline 6 & $T_{3}=2 T_{0}, T_{1}=T_{2}=T_{0}$ & $153,742,852.666$ & $12,811,904.39$ \\
\hline 7 & $T_{1}=T_{2}=2 T_{0}, T_{3}=T_{0}$ & $119,439,647.395$ & $9,953,303.95$ \\
\hline 8 & $T_{1}=T_{3}=2 T_{0}, T_{2}=T_{0}$ & $138,843,599.382$ & $11,570,299 / 95$ \\
\hline 9 & $T_{2}=T_{3}=2 T_{0}, T_{1}=T_{0}$ & $114,283,199.347$ & $9,523,599.95$ \\
\hline 10 & $T_{1}=3 T_{0}, T_{2}=T_{3}=T_{0}$ & $153,963,032.485$ & $12,830,262.71$ \\
\hline 11 & $T_{2}=3 T_{0}, T_{1}=T_{3}=T_{0}$ & $121,378,931.848$ & $10,114,910.99$ \\
\hline 12 & $T_{3}=3 T_{0}, T_{1}=T_{2}=T_{0}$ & $147,150,744.420$ & $12,262,562.04$ \\
\hline 13 & $T_{1}=T_{2}=3 T_{0}, T_{3}=T_{0}$ & $101,543,410.335$ & $8,461,950.86$ \\
\hline
\end{tabular}




\begin{tabular}{|l|l|l|l|}
\hline 14 & $T_{1}=T_{3}=3 T_{0}, T_{2}=T_{0}$ & $127,315,222.908$ & $10,609,601.91$ \\
\hline 15 & $T_{2}=T_{3}=3 T_{0}, T_{1}=T_{0}$ & $94,731,122.271$ & $7,894,260.19$ \\
\hline 16 & $T_{1}=T_{2}=2 T_{0}, T_{3}=3 T_{0}$ & $92,791,837.818$ & $7,732,653.15$ \\
\hline 17 & $T_{1}=T_{3}=2 T_{0} T_{2}=3 T_{0}$ & $86,423,977.233$ & $7,201,998.10$ \\
\hline 18 & $T_{2}=T_{3}=2 T_{0} T_{1}=3 T_{0}$ & $94,447,677.834$ & $7,870,639.82$ \\
\hline 19 & $T_{1}=2 T_{0}, T_{2}=T_{3}=3 T_{0}$ & $79,831,868.987$ & $6,652,655.75$ \\
\hline 20 & $T_{2}=2 T_{0}, T_{1}=T_{3}=3 T_{0}$ & $87,855,569.588$ & $7,321,207.46$ \\
\hline 21 & $T_{3}=2 T_{0}, T_{1}=T_{3}=3 T_{0}$ & $81,487,709.004$ & $6,790,642.42$ \\
\hline 22 & $T_{1}=T_{0}, T_{2}=2 T_{0}, T_{3}=3 T_{0}$ & $107,691,090.901$ & $8,974,257.58$ \\
\hline 23 & $T_{2}=T_{0}, T_{1}=2 T_{0}, T_{3}=3 T_{0}$ & $132,251,490.937$ & $11,020,957.58$ \\
\hline 24 & $T_{3}=T_{0}, T_{1}=2 T_{0}, T_{2}=3 T_{0}$ & $106,479,678.364$ & $8,873,306.53$ \\
\hline
\end{tabular}

This flow station has three machines: two centrifugal pumps and a diesel generator. The expected failure cost for one month inspection interval is presented in Table 1. The failure cost for machine one, two and three are: N28, 605,084,641; N85, 350,520.766 and $\mathrm{N} 41,127,460.050$. For a two months inspection interval, the expected failure costs are: $\mathrm{N} 15,715,851.458 ; \mathrm{N} 47,900,887.547$ and N23,081,778.818. Machine two contributes the highest failure cost, followed by machine three and machine one respectively. For three months inspection interval, the failure costs are: $\mathrm{N} 11$, 449,579.209; $\mathrm{N} 35,610,914.697$ and $\$ 17,159,666.553$ respectively. The total failure cost for one month, two months and three months inspection intervals are: $\mathbb{1} 155,083,065.457$; $\mathbb{N} 86,698,517.823$ and $\mathbf{N} 64,220,160.458$ respectively.

The inspection cost is $\mathbb{N} 335,000$ and the depreciated instrument cost is $\mathbb{N} 6,655,440$.

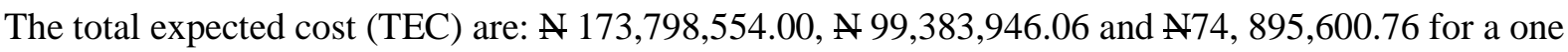
month, two months and three months inspection interval.

For a three machine system, 24 options are available. For this system, the optimum inspection interval is three months for all the machines. Other TEC cost options for a decision maker are presented in Table 4.

A Gantt Chart of the machine inspection for the system is presented in Table 5.

Table5. Gantt Chart for Machine Inspection at Flow Station.

\begin{tabular}{|c|c|c|c|c|c|c|c|c|c|c|c|c|c|}
\hline \multirow{2}{*}{$\begin{array}{l}\text { M/C } \\
\text { NO. }\end{array}$} & \multirow{2}{*}{$\begin{array}{l}\text { Machine } \\
\text { Type }\end{array}$} & \multicolumn{12}{|c|}{ Months } \\
\hline & & 1 & 2 & 3 & 4 & 5 & 6 & 7 & 8 & 9 & 10 & 11 & 12 \\
\hline 1 & Pump & & & $\bullet$ & & & $\bullet$ & & & $\bullet$ & & & $\bullet$ \\
\hline 2 & Pump & & & $\bullet$ & & & $\bullet$ & & & $\bullet$ & & & $\bullet$ \\
\hline 3 & Generator & & & $\bullet$ & & & $\bullet$ & & & $\bullet$ & & & $\bullet$ \\
\hline
\end{tabular}

\section{CONCLUSION}

For a three machine system as shown, 24 options are possible. For this system the optimum inspection interval is three months for all the machines. These results show the efficacy of combinatorial optimization for a CBM system. An algorithm that can generate these combinations automatically for any number of machines with a basic cycle and multiples of basic cycle in a system is highly recommended for development.

\section{REFERENCES}

[1] Al-Najjar, B. (1991) "On The Selection of The Condition Based Maintenance for Mechanical Systems", in Holmberg, K and Folkerson, A. (Eds.) Operational Reliability and System Maintenance, Elsevier Science, pp. 153-173.

[2] Haritha, S. (2002) "Relevant Condition Parameter Strategy for An Effective Condition-Based Maintenance". Journal of Quality in Maintenance Engineering, Vol. 8, No. 1, pp. 92-105.

[3] Bengtsson, M. (2004) Condition Based Maintenance in Technical Systems. (Online serial) Available:http://www.idp.mdh.se/forskninj/amneri/productprocess/projetk/cbm /index - asp? Prpb 106 [June 16, 2013]. 
[4] Banga, T. R., Agwai, N. K. and Sharma, S.C. (1992) Industrial Engineering and Management Sciences. $7^{\text {th }}$ Ed. Kharma Publishers, Delhi, p. 662. Monitoring Process"' European Journal of Operational Research 82(2) 258-269

[5] Evans, J. P. (2003) "Utilizing Advanced Monitoring and Diagnostics Technologies to Implement a Condition-based Maintenance Programme. (Online serial) Available: http://images.tdworldexpo.com /files/ 1104/MT6\%20-\%20-\%Evans.pdf. [June 10, 2013].

[6] Goode, K.B.; Roylance, B.J. and Moore, J. (1998): “ The development of Predictive Model for ConditionBased Maintenance in a Steel Works Hot Strip Mill",

[7] Guerin, D. (1977) “Condition Monitoring”' The Production Engineering. March pp. 88-91.

[8] ISO 2372 (10816) Severity Chart for Vibration

[9] Koboa-Aduma, B. (1991) "Maintenance Management of Small scale Industries", in the Proceedings of the International Conference Workshop on Engineering for Accelerated Rural Faculty of Engineering, University of Nigeria, Nsukka. 243

[10] Laakso, K. and Rosqvist, T. (2002) The Use of Condition Monitoring Information for Maintenance Planning and Decision -Making. VTT Industrial System, Finland.

[11] Moubray, J. (2002) An Introduction to Predictive Maintenance. New York: Industrial Press.

[12] Akpan, W.A.; Odukwe, A.O. ;Okorie, B.A.(2017.)'Mathematical modelling of maintenance scheduling based on condition monitoring'. American journal of engineering research, Vol.6 issue 8

Citation: Akpan W. A, et.al., (2019). "Combinatorial Optimization in Condition Based Maintenance System”. International Journal of Research Studies in Computer Science and Engineering (IJRSCSE), 6(4), pp.16-23. http://dx.doi.org/10.20431/2349-4859.0604003

Copyright: (C) 2019 Authors, this is an open-access article distributed under the terms of the Creative Commons Attribution License, which permits unrestricted use, distribution, and reproduction in any medium, provided the original author and source are credited. 